\title{
Manganese Deposition Content in Carbon Nanotubes Based Filters: Energy Dispersive X-ray and Rutherford Backscatter Spectrometry Investigations
}

\author{
Emad M. Elsehly \\ Physics Department, Faculty of Science, Damanhour University, Damanhour, Egypt \\ E-mail: elsehlyfigo@yahoo.com
}

Received: 10 September 2020; Revised: 25 November 2020; Accepted: 11 December 2020

\begin{abstract}
Carbon nanotubes (CNTs) based filters have a prospective advantage compared to the commercial filters due to their lightweight and ability to work without electricity or heat. The manganese $(\mathrm{Mn})$ removal from aqueous solutions by oxidized multi-walled carbon nanotubes (O-MWCNTs) was investigated. The filtration performance was studied under ambient conditions: the solution $\mathrm{pH}$, the initial manganese concentration, and the MWCNT-filter mass. The samples of MWCNT-filters were investigated using energy dispersive X-ray spectroscopy (EDS) and rutherford backscatter spectrometry (RBS) to account for the manganese content within the MWCNT-filter. These techniques were conducted to study the oxidation effect on the morphology of MWCNTs and evaluate the oxygen functional groups and the average diameter distribution. Based on these examinations, the competence of Mn removal may exceed $91 \%$ for $50 \mathrm{ppm}$ initial concentration of Mn, proposing that functionalized MWCNTs is a promising filter. The Mn removal was achieved at low $\mathrm{pH}$ with removal enhancement at the $\mathrm{pH}$ of 2. Functionalized MWCNTs based filters are promising candidate for heavy metal ions removal from industrial wastewater.
\end{abstract}

Keywords: RBS, manganese, MWCNT, MWCNT-filters, EDS

\section{Introduction}

The contamination of water resources caused by the disposal of heavy metals has induced worldwide concern. The water crisis is one of the biggest challenges of our time. Water demand is growing rapidly as the result of population growth and rapid urbanization. However, in densely populated areas and arid regions, water resources are limited. The shortage of water resources calls for effective wastewater and desalination innovations [1]. Heavy metal pollutants such as iron have been a major concern for many years due to their toxicity to aquatic life, plants, animals, human beings and the environment $[2,3]$.

Manganese is a very common compound that can be found everywhere. It is available in the environment as suspended particulates resulting from mechanical discharges, soil disintegration and volcanic emanations [4]. Manganese is an essential metal for the human system and many enzymes are activated by manganese, but it is toxic when higher concentrations are present in the human body. Manganese ion concentrations of above 0.05 milligram per liter (mg/l) might be poisonous to most microorganisms [5]. Manganese impacts occur primarily in the respiratory tract and in the brain [6]. It may also occur at the origin of corrosion in sewers due to the development of microorganisms and bacteria, which cause not only health problems but also odors, corrodes plumbing equipment, and reduce well

Copyright (C2021 Emad M. Elsehly

DOI: https://doi.org/10.37256/nat.222021961

This is an open-access article distributed under a CC BY license

(Creative Commons Attribution 4.0 International License)

https://creativecommons.org/licenses/by/4.0/ 
yields section [7].

Basic techniques for eliminating metals from water, for example, ion exchange, reverse osmosis and electrodialysis have been demonstrated to be either excessively costly or wasteful to eliminate heavy metal particles from fluid arrangements [8-11]. At present, chemical treatments are not used due to disadvantages such as high maintenance costs. The advent of nanotechnology for the purification of water has brought a lot of hope. The success of CNT membranes as filters is based on their unique properties, including high surface area, and good mechanical and thermal stability [12-15]. Despite having smaller pores, CNTs have high permeability and lower pressure and are required to pump water through the filter, possibly due to the smooth interior of the CNT [16]. The main advantage of this is that the cost of energy savings is reduced. For example, their applicability to the removal of hazardous pollutants from aqueous streams has been extensively studied $[17,18]$. The surface of carbon nanotubes is initially inert and solophobic, which means that the practical effect of the application of CNTs, particularly in the filtration of solutions, is lower than expected [19]. A potential answer to this issue is the oxidation of the outside of carbon nanotubes. During oxidation treatment, undefined carbon and reactant particles presented by the chemical vapor deposition (CVD) planning measure were removed. The functionalization of CNT surfaces with oxygen-containing groups in this study was performed by treatment with concentrated nitric acid oxidation technique [20]. Multi-walled carbon nanotubes (MWCNTs) have recently been utilized to eliminate metal particles, for example, lead, copper, cadmium, silver, nickel [21]. Kandah and Meunier have discovered that the adsorption of $\mathrm{Ni}^{2+}$ by oxidized CNTs is 1.24 times higher than commercial activated carbon [22-24].

The objectives of the present work are (a) to investigate the process of purification and functionalization of MWCNTs by nitric acid oxidation and (b) to study the filtration efficiency of manganese by MWCNT (Taunit-M-filter) as a function of iron solution $\mathrm{pH}$, ion concentrations and $\mathrm{CNT}$ doses.

\section{Methods}

\subsection{Characterization of the MWCNT-filter}

The material of this investigation is the commercial MWCNTs. The "MWCNTs" used was delivered by the Nanotech Center in Tambov, Russia. This material is a free dark powder, comprising of grainy agglomerates of MWCNTs with the size of a few micrometers. Their geometric parameters and physical properties are shown in Table 1. The MWCNT channels were set up by sandwiching the packed MWCNTs between two bits of glass fiber channel and placed into a needle.

\subsection{Manganese stock solution preparations}

For the preparation of manganese stock solution, $1 \mathrm{~g}$ of $\mathrm{KMnO}_{4}$ was added into $1000 \mathrm{ml}$ of distilled water. The prepared stock arrangement was made with a centralization of $1000 \mathrm{ppm}$ and weakened to the ideal fixation.

Table 1. MWCNT specifications in this study

\begin{tabular}{cc}
\hline Parameter/CNTs & MWCNTs \\
\hline The outer diameter $(\mathrm{nm})$ & $(12-40)$ \\
The interior diameter $(\mathrm{nm})$ & $(3-8)$ \\
Tube length $(\mu \mathrm{m})$ & 2 and more \\
The specific surface $\operatorname{area}\left(\mathrm{m}^{2} / \mathrm{g}\right)$ & $(120-130)$ \\
The bulk density $\left(\mathrm{g} / \mathrm{cm}^{3}\right)$ & $(0.04-0.06)$ \\
\hline
\end{tabular}




\subsection{Nitric acid functionalization of MWCNT-filter}

The surface functionalization was performed by utilizing an ultrasonic technique $(35 \mathrm{kHz}) .0 .5 \mathrm{~g}$ of MWCNTs was measured and afterward added to $100 \mathrm{ml}$ of concentrated nitric corrosive. The blend arrangement was then sonicated at $80{ }^{\circ} \mathrm{C}$ in the water shower for 10 hours. Then, the blend was sifted and washed a few times with deionized water until its $\mathrm{pH}$ level reached the value of 7 . The working MWCNTs were dried in the broiler at $80{ }^{\circ} \mathrm{C}$ for the entire evening. Rutherford backscatter spectrometry (RBS) was used to investigate the Mn deposition content (Rutgers General Ionex tandem accelerator is capable of producing $\mathrm{He}^{+2}$ ions up to $5.1 \mathrm{MeV}$ via a multi-stage acceleration process).

\subsection{Experimental procedure}

Table 2 shows the test boundaries and their varieties. The expulsion productivity $(R)$ is characterized as follows:

$$
\mathrm{R}=\frac{K_{O}-K}{K_{O}} \times 100
$$

Where $K_{O}$ and $K$ are the fluid arrangement conductivity, before and after filtration $(\mu \mathrm{S} / \mathrm{cm}), K=C \Lambda$, where $\Lambda$ is the molar conductivity in $\mu \mathrm{S} /(\mathrm{cm} \cdot \mathrm{mol})$, and $C$ is the convergence of manganese in the arrangement in $\mathrm{mol}^{-1}$.

Table 2. The variation in the removal parameters

\begin{tabular}{cccc}
\hline \multirow{2}{*}{ Parameter } & \multicolumn{3}{c}{ Variations } \\
\cline { 2 - 4 } & Low & Middle & High \\
\hline 1. Manganese initial concentration $(\mathrm{ppm})$ & 50 & 100 & 200 \\
2. The $\mathrm{pH}$ of manganese in the aqueous solution & 2 & 7 & 10 \\
3. MWCNT-filter mass $(\mathrm{g} / 50 \mathrm{ml})$ & 0.2 & 0.4 & 0.6 \\
\hline
\end{tabular}

\section{Results and discussions}

\subsection{Investigation of acid functionalized MWCNT-filters}

The structure of raw and oxidized MWCNT was characterized by SEM (TESCAN) and transmission electron microscope (TEM). As shown in Figure 1, strong decrease in nanotube diameters was observed, followed by shorter tube length. For EDS analysis, both of pristine and oxidized MWCNT tablets were controlled identically by the same weight [4]. It can be seen from the EDS study that the oxygenated groups were enhanced after chemical functionalization, as shown in Figure 2 (b). From Figure 2 (c), Manganese deposition is clearly seen on the oxidized MWCNT after filtration. The presence of the metallic elements such that $\mathrm{Co}, \mathrm{Mg}$ and $\mathrm{Al}$ in pristine MWCNTs come from the synthesis procedure and these elements were removed after oxidation process [13]. The structure of MWCNTs was confirmed in Figure 2 (d). Here, we also mention a strong technique to investigate the metal content of oxidized MWCNT filter, known as Rutherford backscatter spectrometry (RBS). Two samples of CNT-filters, before and after filtration, were irradiated simultaneously with a $1.5 \mathrm{MeV}\left(\mathrm{He}^{4}\right)$ ion beam, a 155 scattering angle and a $25 \mathrm{keV}$ resolution. The RBS analysis shows the deposition of manganese to the oxidized MWCNT, as shown in Figure 3. 


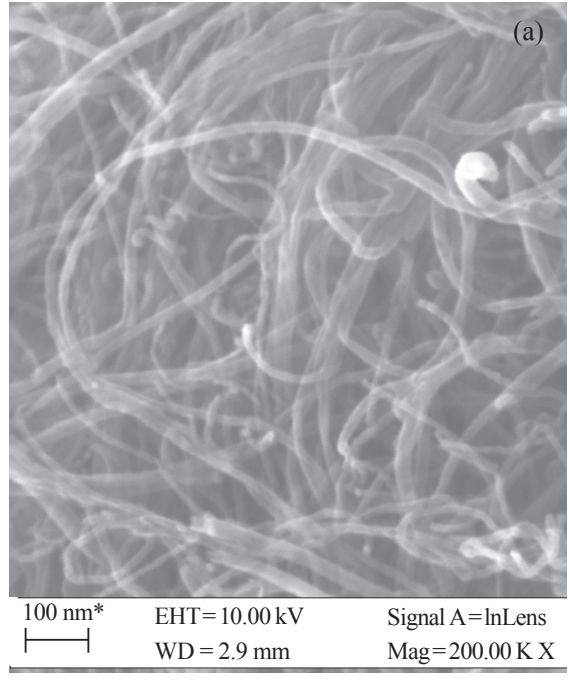

(a) Average diameter $=25 \mathrm{~nm}$

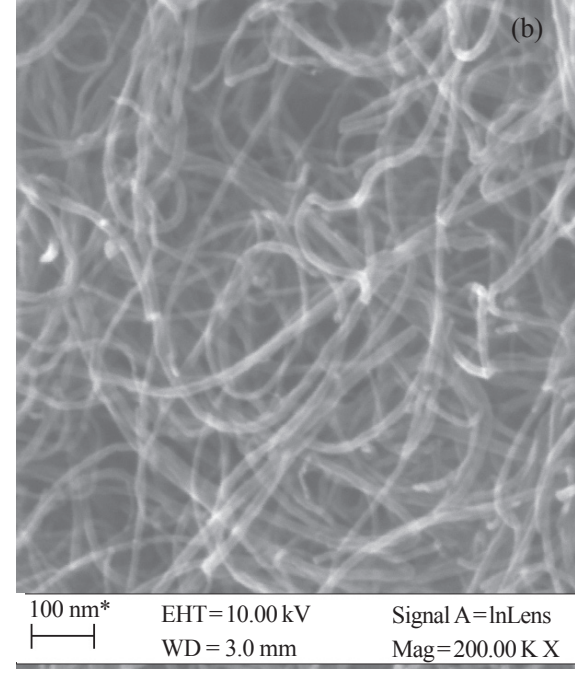

(b) Average diameter $=16 \mathrm{~nm}$

Figure 1. SEM analyses of the average tube diameter of MWCNT-filters (a) before, and (b) after chemical functionalization
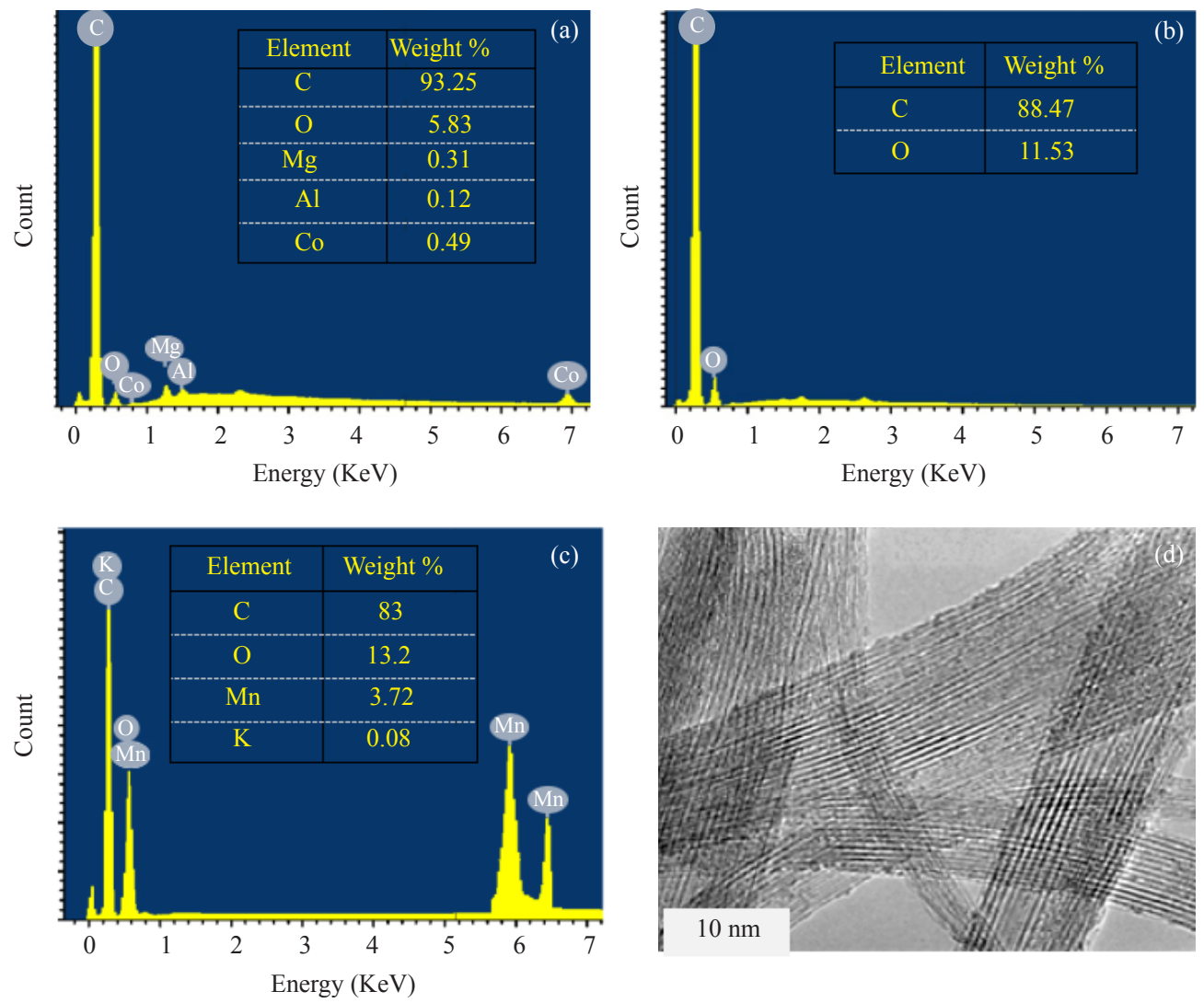

Figure 2. EDS study of (a) grown MWCNTs, (b) after chemical oxidation, and (c) oxidized Taunit following the manganese filtration from the aqueous solution and (d) HR-TEM of the MWCNTs 

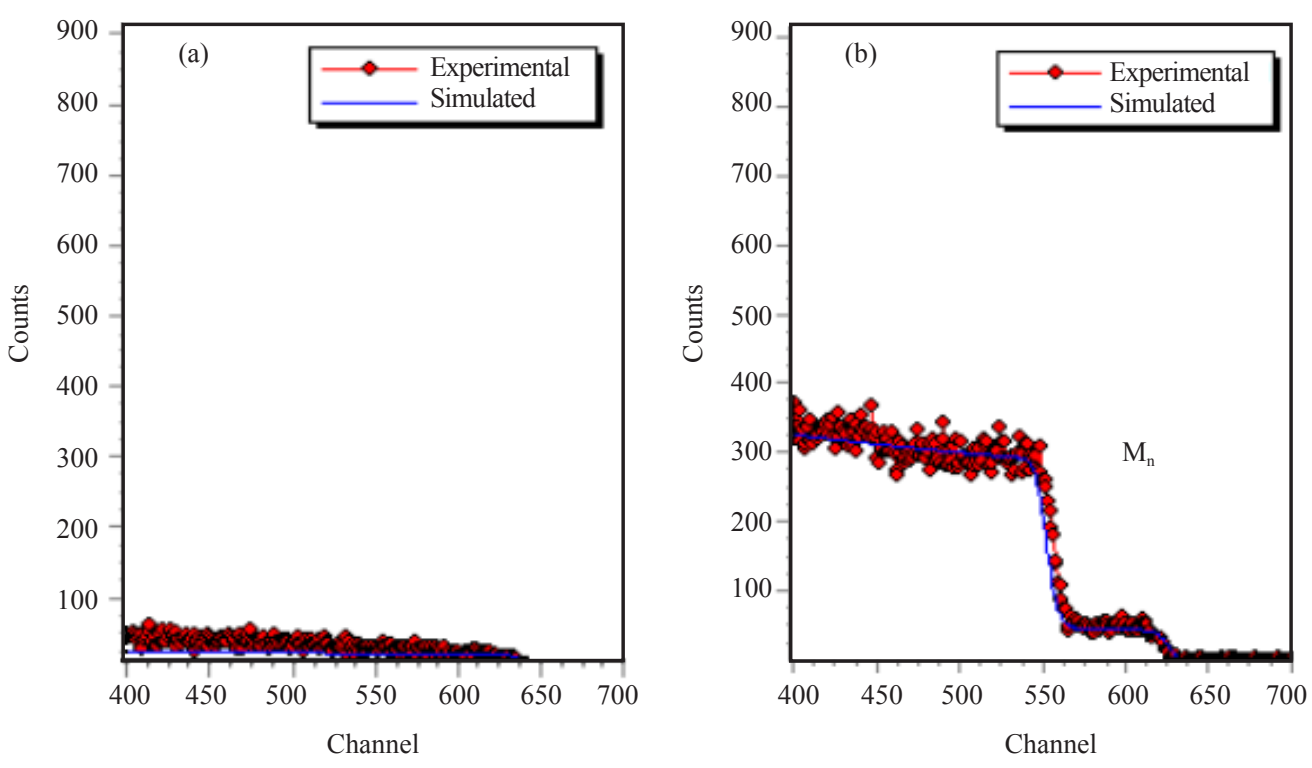

Figure 3. RBS analyses of MWCNTs filter: (a) before and (b) after filtration

\subsection{Contact time and removal performance}

The filtration performance is associated with the deposition time required by the manganese ions in the aqueous solution getting in touch with the MWCNTs filter. Significant parameters such as deposition time, flow rate and contact time can be roughly estimated using pervious report [15]. In our test, manganese arrangement fixation was 50 ppm with $\mathrm{pH}=2$ and the filter dosage of $600 \mathrm{mg}$. The height and the dynamic zone of the MWCNTs filter are $4 \mathrm{~mm}$ and $3 \mathrm{~cm}^{2}$, respectively. From Table 3, for the contact time of $0.36 \mathrm{~min}$, the filtration performance for F-MWCNT filters is higher and the removal efficiency could reach $91.5 \%$. Likewise, the flow rate of the manganese solution during the filtration process by F-MWCNT filters is higher than the P-MWCNT [4]. The squat contact time of the F-MWCNT filters maintains the relevance of ozone functionalized MWCNT as efficient adsorbents.

Table 3. Filtration parameters including the deposition time of filtration process, stream rate, the contact time, and the efficiency of removal for P-MWCNT and F-MWCNT filters

\begin{tabular}{ccccc}
\hline Parameter & Deposition time $(\mathrm{min})$ & Flow rate $(\mathrm{cm} / \mathrm{min})$ & Contact time $(\mathrm{min})$ & Removal efficiency $(\%)$ \\
\hline P-MWNT & 25 & 0.49 & 0.67 & 67 \\
O-MWNT & 15 & 0.96 & 0.36 & 91.5 \\
\hline
\end{tabular}

\subsection{The consequence of manganese ionic concentration}

A relative investigation of the crude and oxidized MWCNTs filtration effectiveness of manganese expulsion is preceded as a component of the manganese fixation in the watery arrangement. Table 4 shows that, with an expansion in the underlying grouping of manganese in the watery arrangement, the expulsion proficiency $(R)$ diminishes. At 200 ppm, $R$ is only $45 \%$ for $0.6 \mathrm{~g}$ of immaculate MWCNTs. However, for a similar volume of oxidized MWCNTs the presentation is $68 \%$, while at a low centralization of $50 \mathrm{ppm}, R$ of oxidized MWCNTs is around $91.5 \%$. The value of the removal efficiency in this study is higher than the result obtained in [4]. This suggests that the adsorption interaction between oxidized MWCNTs and manganese ions was primarily of an ion interaction type consistent with the ion exchange mechanism; as shown in Figure 4. Solid manganese focus confines its change to oxidized MWCNT surfaces. These results showed the strong relation between the conductivity and ionic strength during the filtration process. So the 
reduction in conductivity of the solution is an indicator of the concentration decrement of manganese.

Table 4. The removal efficiency as a function of the initial ionic concentration of $\mathrm{Mn}$ in water solution $(C)$ with pristine MWCNT-filter (P-MWCNT) and functionalized (O-MWCNT) at $\mathrm{pH}=7$

\begin{tabular}{cccccc}
\hline$C(\mathrm{ppm})$ & $\mathrm{K}(\mu \mathrm{S})$ before filtration & $\begin{array}{c}\mathrm{K}(\mu \mathrm{S}) \text { after filtration } \\
(\mathrm{P}-\mathrm{MWCNT})\end{array}$ & $\begin{array}{c}\mathrm{K}(\mu \mathrm{S}) \text { after filtration } \\
(\mathrm{O}-\mathrm{MWCNT})\end{array}$ & $\mathrm{R} \%$ (P-MWCNT) & $\mathrm{R} \%(\mathrm{O}-\mathrm{MWCNT})$ \\
\hline 200 & 762 & 495 & 395 & 45.04 & 68.16 \\
100 & 191 & 98 & 68 & 56.70 & 79.40 \\
50 & 49 & 22 & 12 & 67.10 & 91.50 \\
\hline
\end{tabular}

\subsection{The pH effect on the removal of $\mathrm{Mn}$}

The $\mathrm{pH}$ esteem is one of the most basic measures for directing the period of metal particle sorption. The impact of $\mathrm{pH}$ on manganese evacuation is concentrated by estimating three $\mathrm{pH}(2,7$ and 10) and $50 \mathrm{ppm}$ manganese esteems with a channel mass of $0.6 \mathrm{~g}$. Figure 5 shows that the most extreme evacuation of manganese happens at the $\mathrm{pH}$ level of 2, as the expulsion effectiveness $(\mathrm{R})$ could reach $85.7 \%$ for oxidized MWCNTs, while $\mathrm{R}$ is about $63 \%$ at $\mathrm{pH}=10$. From Figure 5, the expulsion of manganese from the fluid arrangement of oxidized MWCNTs is more powerful than crude MWCNTs. Explicit gatherings, for example, $-\mathrm{OH}$ and $-\mathrm{COOH}$ on the outside of oxidized MWCNTs, are expected to have oxidized MWCNTs as carbonaceous material, for example, $\mathrm{C}_{\mathrm{x}} \mathrm{OH}$ where $\mathrm{C}_{\mathrm{x}}=$ carbon. It is important to take note that the hydroxylated surface gatherings shift at various $\mathrm{pH}$ esteems due to the protonation/deprotonation measures [15] (i.e., $\mathrm{C}_{\mathrm{x}} \mathrm{OH}+\mathrm{H}^{+} \leftrightarrow \mathrm{C}_{\mathrm{x}} \mathrm{OH}^{2+}$ at low $\mathrm{pH}$, and $\mathrm{C}_{\mathrm{x}} \mathrm{OH} \leftrightarrow \mathrm{C}_{\mathrm{x}} \mathrm{O}^{-}+\mathrm{H}^{+}$at high $\mathrm{pH}$ ). The contrarily charged $\mathrm{MnO}_{4}$ can be immediately adsorbed to oxidized MWCNTs at low $\mathrm{pH}$ esteems and is hard to adsorb at high $\mathrm{pH}$ esteems. At high $\mathrm{pH}$ levels, the more prominent the valence of the adsorbed anions, the more negative the surface turns out to be, repressing further anion adsorption. Two kinds of techniques are ordinarily utilized for the expulsion of manganese: the main sort of evacuation of $\mathrm{MnO}_{4}$ anions straightforwardly by surface complexation, while the subsequent sort relies upon the decrease of $\mathrm{MnO}_{4}$ to $\mathrm{Mn}$ (II) cations acquired by particle trade, as shown in Figure 4.
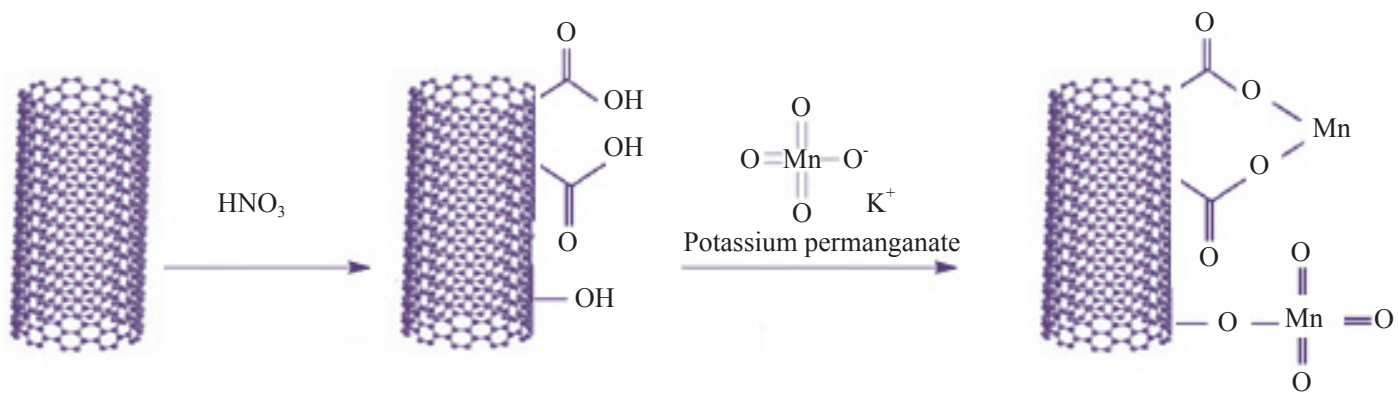

Figure 4. The interaction mechanism of Mn with functionalized MWCNT-filters 


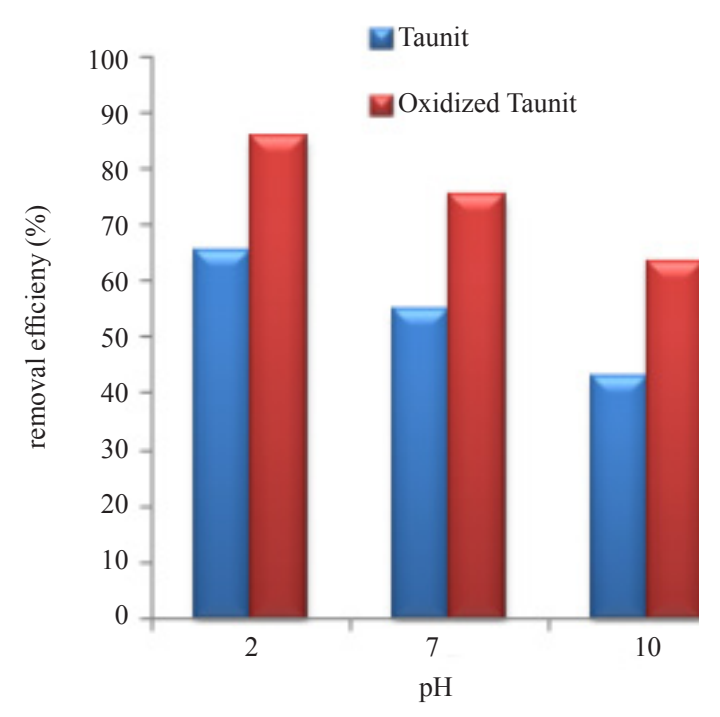

Figure 5. $\mathrm{pH}$ variation with removal efficiency of Manganese

\subsection{Filter mass effect and the removal efficiency}

Figure 6 indicates improved manganese removal efficiency with the increment of MWCNT dosage. This phenomenon suggested that filtration relied on the existence of binding sites. Oxidation treatment had a clear impact on the MWCNT removal efficiency of manganese. It is also clear that the oxidation efficiency of oxidized MWCNTs was higher than that of raw MWCNTs. Oxidized MWCNTs have a more variable surface area than untreated MWCNTs. It is understood that carbon surface oxidation can provide not only a higher specific surface area, but also a greater number of functional oxygen-containing groups, which increase the ion exchangeability of carbon materials [23].

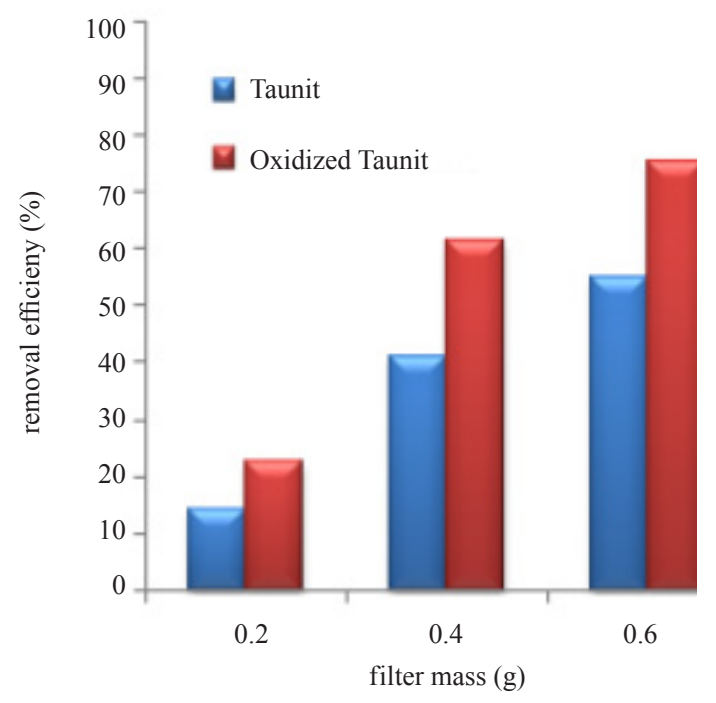

Figure 6. Variation in the removal efficiency of Mn with mass of MWCNTs at $\mathrm{pH}=7$ and $C=50 \mathrm{ppm}$

\section{Conclusion}

One of the pioneer researches is the use of carbon nanotubes for the separation of heavy metal ions from liquid 
solutions. The use of both raw and oxidized CNTs as possible filters to extract manganese from aqueous solutions was explored in this report. Some parameters were found to be significant for the determination of the removal efficiency; the concentration of metals in aqueous solution; $\mathrm{pH}$ and the filter mass. All the parameters used in the filter experiment were important and had the direct effect on the removal efficiency found in the regression study. Strong methods, EDS and RBS, have been used to analyze the oxygen content of oxidized MWCNT and manganese accumulation of the CNT-filter. Based on the data collected, the adsorption of manganese on oxidized MWCNTs can be due to surface complexation rather than to ion exchange involving surface functional groups of oxidized MWCNTs. From the characterization of the Taunit-M-filter, it was observed that the association of manganese with oxidized CNTs was higher compared to raw CNTs. This is due to the fact that oxidation produces classes of oxygen, decreases the diameter of carbon tubes and eliminates impurities. It was also noted that the main factors support the reduction performance of manganese, low $\mathrm{pH}$ and low initial concentration. The unit cost of MWCNTs is predicted to be more lowered in the future so that MWCNTs can potentially be cost-effective adsorbents. Thus, MWCNTs have strong standards for the advancement of wastewater treatment and the elimination of environmental pollution.

\section{References}

[1] Sheikholeslami R. Strategies for future research and development in desalination challenges ahead. Desalination. 2009; 248(1-3): 218-224.

[2] Shannon MA, Bohn PW, Elimelech M, Georgiadis JG, Marinas BJ, Mayes AM. Science and technology for water purification in the coming decades. Nature. 2008; 452(7185): 301-310.

[3] Macedonio F, Drioli E, Gusev AA, Bardow A, Semiat R, Kurihara M. Efficient technologies for worldwide clean water supply. Chemical Engineering and Processing. 2012; 51: 2-17.

[4] Forstner U, Wittmann GTW. Metal Pollution in the Aquatic Environment. Berlin, Heidelberg: Springer; 1983.

[5] Elsehly EM, Chechenin NG, Makunin AV, Motaweh HA, Shemukhin AA. Enhancement of CNT-based filters efficiency by ion beam irradiation. Radiation Physics and Chemistry. 2018; 146: 19-25.

[6] Forstner U, Wittmann GTW. Metal Pollution in the Aquatic Environment. Berlin, Heidelberg: Springer; 1983.

[7] Akpomie KG, Dawodu FA. Simultaneous adsorption of $\mathrm{Ni}$ (II) and $\mathrm{Mn}$ (II) ions from aqueous solution unto a Nigerian kaolinite clay. Journal of Materials Research and Technology. 2014; 3(2): 129-141.

[8] Oehmen A, Viegas R, Velizarov S, Reis MAM, Crespo JG. Removal of heavy metals from drinking water supplies through the ion exchange membrane bioreactor. Desalination. 2006; 199(1-3): 405-407.

[9] Penate B, Garcia-Rodriguez L. Current trends and future prospects in the design of seawater reverse osmosis desalination technology. Desalination. 2012; 284: 1-8.

[10] Ganesan P, Kamaraj R, Sozhan G, Vasudevan S. Oxidized multiwalled carbon nanotubes as adsorbent for the removal of manganese from aqueous solution. Environmental Science and Pollution Research. 2013; 20(2): 987996.

[11] Corry B. Designing carbon nanotube membranes for efficient water desalination. The Journal of Physical Chemistry B. 2008; 112(5): 1427-1434.

[12] Jorio A, Dresselhaus G, Dresselhaus MS. Carbon Nanotubes: Advanced Topics in the Synthesis, Structure, Properties and Applications. Berlin, Heidelberg: Springer; 2008.

[13] Elsehly EM, Chechenin NG, Makunin AV, Motaweh H, Leksina EG. Functionalized carbon nanotubes based filters for chromium removal from aqueous solutions. Water science \& Technology. 2017; 75(7-8): 1564-1571.

[14] Elsehly EM, Chechenin NG, Makunin AV, Motaweh HA. Ozone functionalized CNT-based filters for high removal efficiency of benzene from aqueous solutions. Journal of Water Process Engineering. 2018; 25: 81-87.

[15] Elsehly EM, Chechenin NG, Makunin AV, Shemukhin AA, Motaweh HA. Surface functionalization of multiwalled carbon nanotubes by ozone and the enhancement of their environmental applications. Nano Express. 2020; 1(2): 020023. Available from: https://iopscience.iop.org/article/10.1088/2632-959X/abaafd/pdf.

[16] Long QR, Yang RT. Carbon nanotubes as superior sorbent for dioxin removal. Journal of the American Chemical Society. 2001; 123(9): 2058-2059.

[17] Ren X, Chen C, Nagatsub M, Wang X. Carbon nanotubes as adsorbents in environmental pollution management, A review. Chemical Engineering Journal. 2011; 170(2-3): 395-410.

[18] Stafiej A, Pyrzynska K. Adsorption of heavy metal ions with carbon nanotubes. Separation and Purification Technology. 2008; 58: 49-52. 
[19] Chen J, Chen Q, Ma Q. Influence of surface functionalization via chemical oxidation on the properties of carbon nanotubes. Journal of Colloid and Interface Science. 2012; 370(1): 32-38.

[20] Dyachkova TP, Melezhyk AV, Gorsky SY, Anosova IV, Tkachev AG. Some aspects of functionalization and modification of carbon nanomaterials. Nanosystems: Physics, Chemistry, mathematics. 2013; 4(5): 605-621.

[21] Li Y, Ding J, Luan Z, Di Z, Zhu Y, Xu C, Wu D, Wei B. Competitive adsorption of $\mathrm{Pb}^{2+}, \mathrm{Cu}^{2+}$ and $\mathrm{Cd}^{2+}$ ions from aqueous solutions by multiwalled carbon nanotubes. Carbon. 2003; 41(14): 2787-2792.

[22] Kandah MI, Meunier JL. Removal of nickel ions from water by multi-walled carbon nanotubes. Journal of Hazardous Materials. 2007; 146(1-2): 283-288.

[23] Xu D, Tan X, Chen C, Wang X. Removal of Pb (II) from aqueous solution by oxidized multiwalled carbon nanotubes.Journal of Hazardous Materials. 2008; 154(1-3): 407-416.

[24] Elsehly EM. Enhanced removal of Ni (II) from aqueous solutions by effective acid functionalization of carbon nanotube based filters. The Egyptian Journal of Chemistry. 2020; 63(10): 3861-3871.

\section{Author's information}

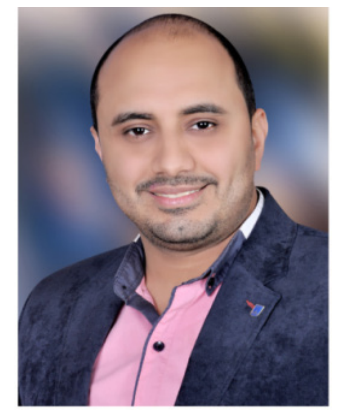

Emad M. Elsehly has previously obtained his $\mathrm{PhD}$ degree-solid state physics in a joint supervision between Moscow State University and Damanhour University. He has awarded his Master degree in theoretical physics from Alexandria University. He has obtained his Bachelor of Science and Education (Category: Excellent with Class Honor), Alexandria University. Emad Elsehly is a lecturer in Damanhour University, faculty of science, Physics department. He has experience with numerous subjects like Quantum Field Theory, Advanced Quantum Mechanics, Material Science (Nanomaterials applications), Nanomaterials Synthesis and Characterization, and thermoelectric materials. He has published in numerous international journals and conferences previously. 